Review Article

\title{
Utilization of AYUSH in public health care system: a review
}

\author{
Chithra Boovaragasamy ${ }^{1}$, Seetharaman $\operatorname{Narayanan}^{2 *}$
}

Department of Community Medicine, Mahatma Gandhi Medical College and Research Institute, Puducherry, India

Received: 15 March 2019

Accepted: 07 May 2019

\section{*Correspondence:}

Dr. Seetharaman Narayanan,

E-mail: seethahere@gmail.com

Copyright: (c) the author(s), publisher and licensee Medip Academy. This is an open-access article distributed under the terms of the Creative Commons Attribution Non-Commercial License, which permits unrestricted non-commercial use, distribution, and reproduction in any medium, provided the original work is properly cited.

\begin{abstract}
India is currently facing shortage of trained health workforce, especially in rural areas. WHO recommends mainstreaming of Complementary \& Traditional systems of medicine as an affordable \& culturally acceptable way towards achieving Universal Health Coverage (UHC). Despite the Government of India operating AYUSH clinics in PHCs for more than 10 years, we know very little about patients attending these clinics. Exploring the reasons for utilization of AYUSH care is of much value for planning to scale up the integration of AYUSH. The required information on utilization of AYUSH services were obtained through a review of the literature in PubMed databases (including MEDLINE) using the medical subject headings (MeSH) terms: 'AYUSH', 'utilization', 'Ayurveda', 'Siddha', 'Homeopathy', 'morbidities'. All such studies which have focussed on profiling of patients who sought care in AYUSH were the individuals who have non-life-threatening chronic diseases or conditions. To improve AYUSH based health care services, it is imperative to understand the acceptability of AYUSH interventions among the general public for the utmost utilization of AYUSH services.
\end{abstract}

Keywords: AYUSH, Profiling, Morbidities, Ayurveda, Siddha

\section{INTRODUCTION}

India is a second most populous country in the world with the population of 136 crore. ${ }^{1}$ Our country has committed to provide Universal Health Coverage (UHC), in order to provide health services to all without any discrimination at an affordable cost ensuring equitable access to achieve the United Nation's Sustainable Development Goals (SDG). ${ }^{2}$

The nation is currently undergoing rapid transitions in multiple facets viz. socio-cultural, economic, demographic and nutritional transitions, among others. India's epidemiological transition is characterized by a shift from a pattern of predominantly infectious diseases to a state of dual burden of diseases where both infectious and chronic non-communicable diseases coexist. The high burden of non-communicable diseases in the country has led to large patient cohorts requiring healthcare for extended years of their life. Thus, the Epidemiological transition the country is undergoing has led to increased utilization of healthcare services and also has forced the healthcare system to adapt to these changes in disease profile. $^{3}$

The National Rural Health Mission [now renamed as National Health Mission (NHM)] paved the way for integrating / mainstreaming AYUSH (Ayurveda, Siddha, Unani, Naturopathy \& Homeopathy) services in to the country's existing healthcare system. Ayurveda, Yoga, Unani, Siddha and Homeopathy were the preferred alternative systems for integration as these were the most prevalent Alternate systems being practiced in the country. The decision for integration was taken primarily to overcome the challenge of the shortage of trained health care professionals and to strengthen the health care service delivery system. ${ }^{4-7}$ 
Despite the Government of India operating AYUSH clinics in PHCs for more than 10 years, we know very little about patients attending these clinics. Knowing the common morbidities that AYUSH clinics cater to and understanding why people choose AYUSH care is valuable information for planning to scale up the integration of AYUSH into the nation's public health care system.

\section{METHODS}

The required information on utilization of AYUSH services were obtained through a review of the literature in PubMed databases (including MEDLINE) using the medical subject headings (MeSH) terms, 'AYUSH', 'utilization', 'Ayurveda', 'Siddha', 'Homeopathy', 'morbidities'. The unpublished, grey literature on AYUSH were also gathered from key public and private stakeholder organizational websites. The period of reference was from the year 2005 to 2018. Nearly 10 of the eligible articles were included for the final report. The articles were preferred based on the published time frame, higher order of study designs (scoping and systematic reviews), and publications by top multilateral agencies (WHO). Analysis of the literature was synthesized into a narrative review report, which highlighted our key findings into profiling of the patients seeking AYUSH care.

\section{PROFILING OF PATIENTS SEEKING AYUSH}

Information on common morbidities who seek care in AYUSH system is limited.

Boopathiraj et al conducted a study profiling the patients who reported to the outpatient department at National Institute of Siddha, Chennai. The study revealed that out of the 1135 patients studied, the top morbidities were related to rheumatology $(33 \%)$, skin $(19.2 \%)$, respiratory system $(9.1 \%)$, neurology $(7.7 \%)$ gastroenterology $(6.5 \%)$ and $\operatorname{ENT}(6.1 \%){ }^{8}$

A study conducted by Kannan et al on the health status of geriatric population attending the special siddha geriatric clinic of a research institute revealed that the common morbidities were $(7.4 \%)$ Tholnoigal, $(0.2 \%)$ PirappurupuNoigal, (0.26\%) SuraNoigal, (20\%) VathaNoigal, (3.3\%) Unavu Mandala Noigal, (7.88\%) Swasa Mandala Noigal, $(6.35 \%)$ MuthiyorPerumNoigal. ${ }^{9}$

A cross sectional study done by Selvaraj et al, reported the morbidity profile of the geriatric outpatients (60 years and above) attending secondary level Siddha health facilities in Erode district of Tamil Nadu. Among the 2710 patients who visited the Siddha facilities, $28.1 \%$ were elderly. The top morbidities were arthritis (45.2\%), neuritis $(8.8 \%)$, diabetes $(6.6 \%)$, bronchial asthma $(5.2 \%)$, hemiplegia $(3.7 \%) .^{10}$
Reddy et al had done a cross sectional study on morbidity profile of patients of the paediatric age groups (15 years and below) attending Siddha OPD in a district of Tamil Nadu. Among the 227 children, most of the children were males $(60.8 \%)$ and belonged to the age group $10-14$ years $(45.8 \%)$. About one-fourth $(26.9 \%)$ of the paediatric patients were found to be new cases. Fungal infections $(24.2 \%)$, primary complex $(21.6 \%)$, bronchitis $(10.1 \%)$ and diarrhoea $(8.4 \%)$ were the top morbidities reported. ${ }^{11}$

A facility based cross sectional study was conducted by Duraisamy et al on the morbidity profile of the adult patients attending Siddha OPD in Erode district of Tamil Nadu. Among the 1720 participants, arthritis (21\%), neuritis (10\%), fungal diseases $(7 \%)$ were the top three morbidities, with arthritis and neuritis being most common morbidities in both males and females. ${ }^{12}$

In the Ayurveda system, a study done by Kant et al showed that the most common morbidities seen in Ayurveda clinic were twak vikar or skin disease (12.3\%), sandhivata or osteoarthritis (10.3\%), and kasa or cough $(8.5 \%){ }^{13}$

A survey of Ayurvedic institutions in Delhi also shows that rickshaw pullers and other working class people turn to Ayurveda for several chronic ailments. The main problem in this situation is the dearth in the supply of medicines to AYUSH hospitals and dispensaries. ${ }^{14}$

All such studies which have focussed on profiling of patients who sought care in AYUSH were the individuals who have non-life-threatening conditions that may be chronic.

\section{CONCLUSION}

The pattern of utilization and health seeking attitude varies for AYUSH Systems. There is scarcity of information available on the utilization of AYUSH systems in India. The common reasons for preferring AYUSH includes: 1. Lesser side effects, 2. Efficacy in chronic diseases management, 3.Improvement in quality of life, 4. Health promotion and preventive potential. ${ }^{15}$ Besides, lack of accessibility to Allopathic Medical services sometimes lead to prefer these services. The common conditions approaching for AYUSH systems include the non-life-threatening conditions that may be chronic like Rheumatoid arthritis and Allied conditions, Osteoarthritis, Joint diseases, conditions with an allergic component in their etiology (e.g. bronchial asthma, skin allergies, eczema, psoriasis etc.); obesity, diabetes mellitus; sequelae of cerebrovascular disorders like hemiplegia and paraplegia; digestive disorders.

To improve AYUSH based health care services, it is imperative to understand the feasibility, efficacy and acceptability of AYUSH interventions among the general public for optimal utilization of AYUSH services. This could be possible by improving the communication 
among the health professionals and masses. The cross referrals among different systems may be improved by conducive physical integration which sequentially resulting the functional integration and cross hybridization of merits among medical systems.

Funding: No funding sources

Conflict of interest: None declared

Ethical approval: Not required

\section{REFERENCES}

1. India Population (LIVE). Available at: http://www. worldometers.info/world-population/indiapopulation/. Accessed on 12 March 2019.

2. National Health policy 2017. Ministry of Health and Family Welfare, Government of India, 2017. Available at: https://mohfw.gov.in/documents /policy. Accessed on 12 September 2018.

3. Sharma R. With only $33 \%$ govt doctors in rural India, 'health for all' a tough task. Available at: https://www.oneindia.com/feature/with-only-33govt-doctors-rural-india-health-all-is-toug1485567.html. Accessed on 15 August 2019.

4. Indian Public Health Standards (IPHS) Guidelines for Primary Health Centers; 2012. Available from: http://health.bih.nic.in/Docs/Guidelines/GuidelinesPHC- 2012.pdf. Accessed 28 September 2016.

5. Department of AYUSH, Ministry of Health \& Family Welfare. Mainstreaming of AYUSH under National Rural Health Mission e Operational Guidelines 2011. Available at: http://indian medicine.nic.in/writereaddata/mainlinkFile/File614. pdf. Accessed on 16 September 2016.

6. Ministry of Health and Family Welfare. National Rural Health Mission e Meeting People's Health Needs in Rural Areas: Framework for Implementation, 2005e2012. Available at: http://nrhm.gov.in/images/pdf/aboutnrhm/nrhmfram eworkimplementation/nrhm-framework-latest.pdf. Accessed 04 September 2016.

7. Shrivastava SR, Shrivastava PS, Ramasamy J. Mainstreaming of Ayurveda, Yoga, Naturopathy, Unani, Siddha, and Homeopathy with the health care delivery system in India. J Traditional Complementary Med. 2015;5(2):116-8.
8. Boopathiraj S, Subramanian M, Selva shunmugam P. Profile of patients reporting at OPD of National Institute of Siddha, Chennai-47. J Siddha. 2008;1(1):1-13.

9. Kannan M, Natarajan S, Sathiyarajeswaran P, Meenakshisundaramurthy $\mathrm{K}$. The health status of geriatric population attending the special siddha geriatric clinic of a research institute. Int $\mathbf{J}$ Health Pharm Sci. 2012;1:36-41.

10. Selvaraj K, Srinivasan M, Duraisamy V, Ramaswamy G, Venugopal V, Chinnakali P. Morbidity profile of elderly outpatients attending selected sub-district Siddha health facilities in Tamil Nadu, India. Ancient Sci Life. 2016;35:212-6.

11. Reddy MM, Nair D, Duraisamy V, Selvaraj K, Chinnakali P, Saya GK. Morbidity profile of children attending Siddha hospitals in a district of Tamil Nadu, South India. Int J Contemp Pediatr. 2015;2:168-71.

12. Duraisamy V. Profile of patients attending Siddha OPD and their perceptions regarding quality of services at Government Hospitals in Erode District, Tamil Nadu [DPHM]. Puducherry, Qld: Jawaharlal Institute of Postgraduate Medical Education and Research; 2015.

13. Kant S, Lohiya A, Ahamed F, Abdulkader RS, Singh AK, Silan V. Comparative morbidity profile of patients attending an Ayurveda clinic and a modern medicine clinic of a primary health center in rural Haryana, India. J Family Med Prim Care. 2018;7:374-9.

14. Sujatha V. What could integrative' medicine mean? Social science perspectives on contemporary Ayurveda. J Ayurveda Integr Med. 2011;2(3):11523.

15. Srikanth N, Bhat S, Singh A, Singh R. Health care seeking attitude and utilization of traditional medicine in India-an overview. World $\mathbf{J}$ Pharmaceutical Res 2015;4(7):722-38.

Cite this article as: Boovaragasamy $\mathrm{C}$, Narayanan S. Utilization of AYUSH in public health care system: a review. Int J Community Med Public Health 2019;6:2730-2. 